\title{
PRELIMINARY STUDY ON SEROLOGICAL, MOLECULAR, HISTOLOGICAL AND CLINICAL EVIDENCE OF CHLAMYDIA SPP. IN POLISH SWINE HERDS*
}

\author{
Krzysztof Rypuła ${ }^{1 \bullet}$, Mateusz Porowski ${ }^{1}$, Marcin Nowak ${ }^{2}$, Aleksandra Kumala ${ }^{1}$, Krzysztof Niemczuk ${ }^{3}$, \\ Katarzyna Płoneczka-Janeczko ${ }^{1}$, Monika Szymańska-Czerwińska ${ }^{3}$, Zygmunt Pejsak ${ }^{4}$ \\ ${ }^{1}$ Division of Infectious Diseases of Animals and Veterinary Administration, \\ Department of Epizootiology with Clinic of Birds and Exotic Animals, \\ Faculty of Veterinary Medicine, University of Environmental and Life Sciences, pl. Grunwaldzki 45, \\ 50-366 Wrocław, Poland \\ ${ }^{2}$ Department of Pathology, Faculty of Veterinary Medicine, University of Environmental and \\ Life Sciences, Norwida 31, 50-375 Wrocław, Poland \\ ${ }^{3}$ Laboratory of Serological Diagnosis, National Veterinary Research Institute, Partyzantów 57, \\ 24-100 Puławy, Poland \\ ${ }^{4}$ Department of Swine Diseases, National Veterinary Research Institute, Partyzantów 57, \\ 24-100 Puławy, Poland \\ •Corresponding author: krzysztof.rypula@up.wroc.pl
}

\begin{abstract}
The main objective of this study was to assess the occurrence of Chlamydia spp. in Polish swine herds by using serological, molecular, and histological methods as well as by clinical manifestation of the suspected infection when reproductive disorders were taken into account. The seroprevalence among examined animals was $5.65 \%(96 / 1698)$, whereas molecular assessment of the pathogen was negative (0/298). The results of our investigation showed that Chlamydia spp. infection in swine may be suspected more often based on clinical manifestation or histological examination than serological or molecular methods.
\end{abstract}

Key words: Chlamydia spp., swine, seroprevalence, PCR, histology

The Chlamydiaceae family, which includes the genera Chlamydia, is a well-recognized cause of disease in many species of animals. Most species within Chlamydiaceae separated from each other early in their evolution, which has resulted in a very broad spectrum of pathogenic strains specific to many animal species (Pallen and Wren, 2007). Within the genera, nine distinct species have been identified. Four of these have been described in pigs, including Chlamydia (C. abortus, C. psittaci,

\footnotetext{
*The research was financed by the Polish State Committee for Scientific Research, Kraków, Poland, project No.: N N308 578240.
} 
C. pecorum, and C. suis) (Longbottom, 2004). The importance of these species has been understood since the first reports published in 1955, yet epidemiology, clinical, and zoonotic information remains largely unknown. Numerous studies have reported the involvement of chlamydiae in porcine reproductive disorders, conjunctivitis, enteritis, pneumonia, polyarthritis, pleuritis, and polyserositis. Studies conducted in the last few years have identified chlamydia species in respiratory syndromes with an etiology that seems to be of a multi-factor nature (Schautteet and Vanrompay, 2011; Rypuła et al., 2012; Wheelhouse and Longbottom, 2012). Moreover, chlamydia has been isolated from both clinically healthy animals as well as those with illness symptoms (Englund et al., 2012; Eggemann et al., 2000). On the other hand, the percentage of asymptomatic swine with proven chlamydia infection based on DNA analysis ranges from $23 \%$ to $88 \%$. In animals presenting with a clinically infectious condition, the percentage of positive results is approximately $79 \%$ in extensive farming and up to $90 \%$ in intensive farming (Becker et al., 2007).

The main objective of this study was to assess the occurrence of Chlamydia spp. in Polish swine herds by using serological, molecular, and histological methods. We also considered the clinical manifestation of the suspected infection by taking into account reproductive disorders.

\section{Material and methods}

The Ethical Committee for Animal Experiments, Wrocław, Poland, approved this study and all owners provided informed consent prior to initiation. The study was performed in swine herds that had no observed clinical signs of disease or problems with reproduction, such as repetition of oestrus, discharges from reproductive tract after delivery, or dead or weak piglets in a litter. The research was conducted on 61 randomly selected swine herds from farms that were classified as small ( $\mathrm{n}=38$, up to 10 sows in a herd), medium ( $\mathrm{n}=15$, up to 50 sows in a herd), or large $(\mathrm{n}=8$, above 500 sows in a herd). In all examined herds, amoxycilin, tiamulin, or tetracycline was used during clinical signs of disease outbreak. Antibiotic growth promoters were not used.

The number of serum samples to diagnose with $\mathrm{p}_{1}=10 \%$ were calculated using Episcope 2.0 according to the formula:

$$
n=\left[1-\left(1-p_{1}\right)^{1 / d}\right] \times\left(N-\frac{d}{2}\right)+1
$$

where:

$n=$ number of sows to diagnose,

$p_{1}=$ probability of detecting at least one infected sow,

$N=$ number of sows in the herds,

$d=$ number of infected sows in the herd. 
A total of 1698 serum samples were collected from piglets after farrowing, gilts, and sows in 2010-2012 to assess Chlamydia spp. infection. Antibodies specific to Chlamydia spp. were detected using a complement fixation test (CFT), which is the accredited method used by the National Veterinary Research Institute in Puławy according to EN ISO/IEC-17025:2005.

Molecular and histological studies were performed in sows from the described herds. Samples were collected from live animals (randomly selected) before the 5th day postpartum. Samples were also collected from sows, which were sent by their owners for slaughter due to long-term reproductive problems. A total of 298 specimens were taken, including 230 scrapings collected with a long cytobrush (Equivet, Germany) and 68 scrapings collected with a scalpel blade from one corner of the uterus as well as the core. Genomic DNA taken with swabs was extracted using the DNeasy Blood \& Tissue Kit (Qiagen, Germany) according to the manufacturer's instructions. Molecular evidence of Chlamydia spp. was performed with the two procedure schemes as follows:

First PCR procedure

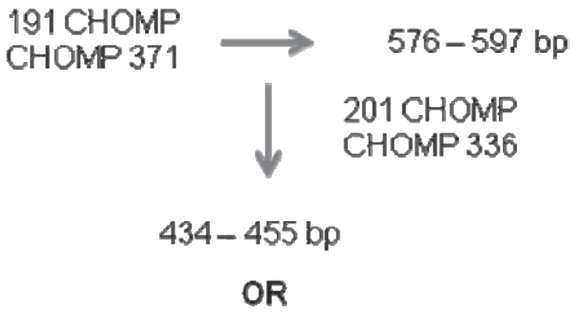

CHOMP 336 218 CHOMP

$389-404$ bp

OR

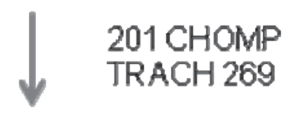

$250 \mathrm{bp}$

The following primers were used in the PCR reaction (Kaltenböck, 1997) in the National Veterinary Research Institute in Puławy procedure (Niemczuk et al., 2007):

191 CHOMP 5'-GCI YTI TGG GAR TGY GCI AC-3'

CHOMP371 5'-TTA GAA ICK GAA TTG ICG RTT IAY GTG IGC IGC-3'

201 CHOMP 5'-GGI GCW GMI TTC CAA TAY GCI CAR TC)

CHOMP 336 5'-CAAGMTTTTCTGGAYTTMAWYTTG TT-3'

TRACH269 5'-ACC ATT TAA CTC CAA TGT ARG GAG TG-3'

218 PSITT 5'-GTA ATT TCI AGC CCA GCA CAA TTY GTG-3'

$\mathrm{K}=\mathrm{G}, \mathrm{T} ; \mathrm{M}=\mathrm{A}, \mathrm{C} ; \mathrm{R}=\mathrm{A}, \mathrm{G} ; \mathrm{W}=\mathrm{A}, \mathrm{T} ; \mathrm{Y}=\mathrm{C}, \mathrm{T} ; \mathrm{I}=$ inosine 
Nested PCR procedure was used as follows. First step of genus-specific reaction with primer set $191 \mathrm{CHOMP/CHOMP371} \mathrm{amplified} \mathrm{a} \mathrm{576-597} \mathrm{base} \mathrm{pair} \mathrm{(bp)} \mathrm{frag-}$ ment of the ompA gene (external amplification). Next secondary PCR was performed with $201 \mathrm{CHOMP/CHOMP} 336$ primers generating an amplicon of 434-455 bp size (internal amplification). In the case of Chlamydiaceae-positive results obtained, $1 \mu \mathrm{l}$ of primary product was used with species-specific sets of primers, 201CHOMP/ TRACH269 or CHOM336/218 PSITT. Amplicons of 250 bp and 389-404 bp were specific for C. suis/C. trachomatis and C. abortus/C. psittaci, respectively.

The final volume of the PCR reaction mixture was $50 \mu \mathrm{L}$, which included $5 \mu \mathrm{L}$ of $10 \times$ PCR buffer, $2 \mu \mathrm{L}$ of $50 \mathrm{mM} \mathrm{MgCl}, 0.2 \mu \mathrm{L}$ of $10 \mathrm{mM}$ dNTP, $1 \mu \mathrm{L}$ of $20 \mathrm{pmol}$ specific primer, $0.2 \mu \mathrm{L}$ of $5 \mathrm{U} / \mu \mathrm{L}$ thermostable polymerase DNA, $39.6 \mu \mathrm{L}$ of sterile water, and $1 \mu \mathrm{L}$ of genomic DNA. Template DNA of C. suis and C. abortus was used as a positive control. The amplification was carried out with a Tepersonal thermocycler (Whatman Biometra, Germany) using the following cycling parameters: 50 cycles of initial denaturation at $97^{\circ} \mathrm{C}$ for $60 \mathrm{~s}$, denaturation at $97^{\circ} \mathrm{C}$ for $60 \mathrm{~s}$, annealing at $50^{\circ} \mathrm{C}$ for $60 \mathrm{~s}$, elongation at $72^{\circ} \mathrm{C}$ for $60 \mathrm{~s}$, followed by a final elongation at $72^{\circ} \mathrm{C}$ for $60 \mathrm{~s}$. The PCR reactions were analysed by electrophoresis on a $1 \%$ agarose gel and visualized by staining with ethidium bromide and ultraviolet transillumination.

\section{Second PCR procedure}

Multiplex PCR was performed with primers specific to ompA/tRNA Gly and to IGS/tRNA for each of the nine species of Chlamydiaceae (Everett et al., 1999). The sequencing of primers used in the reaction was as follows:

$\begin{array}{ll}\text { IGF } & \text { 5'-GACTAGGTTGGGCAAG-3' } \\ \text { IGR } & \text { 5'-AGCTCTTA(T/G/A)(C/T)AACTTGGTCTGTA-3', } \\ 1260 & \text { 5'-TTAATC(A/G)A(T/C)GAAAGAGCTGCTCA-3' } \\ \text { TGLY } & \text { 5'-GGCTACAGCTCTACCATTGA-3' }\end{array}$

The PCR mixture had a total volume of $25 \mu \mathrm{L}$ and contained $17.65 \mu \mathrm{L}$ deionized water, $2.5 \mu \mathrm{L} 10 \mathrm{X}$ reaction buffer with $2 \mathrm{mM} \mathrm{MgCl}_{2}, 0.5 \mu \mathrm{L}$ deoxynucleoside triphosphate, $0.15 \mu \mathrm{L}$ of each primer, $1 \mu \mathrm{L} 1 \mathrm{U}$ RUN polymerase (A\&A Biotechnology, Poland), $2 \mu \mathrm{L}$ of DNA template, and $0.75 \mu \mathrm{L} 50 \mathrm{mM} \mathrm{MgCl}_{2}$. Template DNA of C. suis, $C p$. psittaci and Cp. felis was used as positive controls. The following cycling conditions were used: an initial denaturation at $95^{\circ} \mathrm{C}$ for $3 \mathrm{~min}$, followed by 40 cycles of denaturation at $94^{\circ} \mathrm{C}$ for $30 \mathrm{~s}$, annealing at $55^{\circ} \mathrm{C}$ for $15 \mathrm{~s}$, and elongation at $72^{\circ} \mathrm{C}$ for $30 \mathrm{~s}$, followed by a final elongation at $72^{\circ} \mathrm{C}$ for $5 \mathrm{~min}$. PCR products were detected on a $1.5 \%$ agarose gel stained with ethidium bromide and analysed with GelDoc (Bio Rad, USA) and QuantityOne software (BioRad Laboratories, France). The DNA products from the reactions were $320 \mathrm{bp}$ (ompA/tRNA ${ }^{\text {Gly }}$ ) and $240 \mathrm{bp}$ (IGS/tRNA) in length. Tissue samples (fragments of uteri corners and core uteri) taken for histological studies were fixed for $24 \mathrm{~h}$ in $10 \%$ formalin, transferred to paraffin blocks, and then cut into sections with a $4 \mu \mathrm{m}$ thickness. Specimens were stained with hematoxylin and eosin (H\&E). Micrographs of the stained specimens were subjected to computer-supported image analysis with a computer connected to an Olympus BX53 (Olympus, Japan). Image recording and digital analysis was conducted using software cell^A (Olympus Soft Imaging Solution GmbH, Germany). 


\section{Results}

The seroprevalence for Chlamydia spp. was 5.65\% (96/1698). Molecular evidence of Chlamydia spp. independent of the PCR analysis was negative in all examined specimens. Histological examination $(n=68)$ showed abundant inflammatory infiltration consisting mainly of lymphocytic cells (Figure 1) located in the mucosa and submucosa of uteri. Single neutrophil granulocytes and a few histolytic and plasma cells were observed in the inflammatory infiltration. In some of the preparations, cellular infiltration reached the tunica muscularis with a tendency to surround the blood vessels (Figures 2 and 3). The lesions were found in $20 \%$ of examined tissue samples. Thus, these results indicate that a histological examination without immunohistochemistry or in situ hybridization is only a suboptimal method for diagnosing Chlamydiaceae in pigs and demonstrates rather moderate reliability.

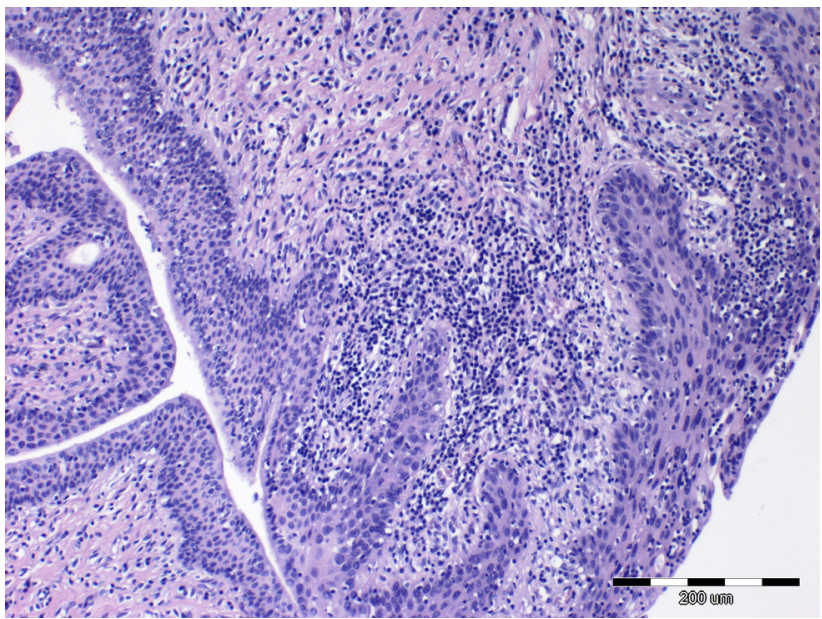

Figure 1. Massive lymphatic infiltration in submucosal and mucosal membranes of the uterus

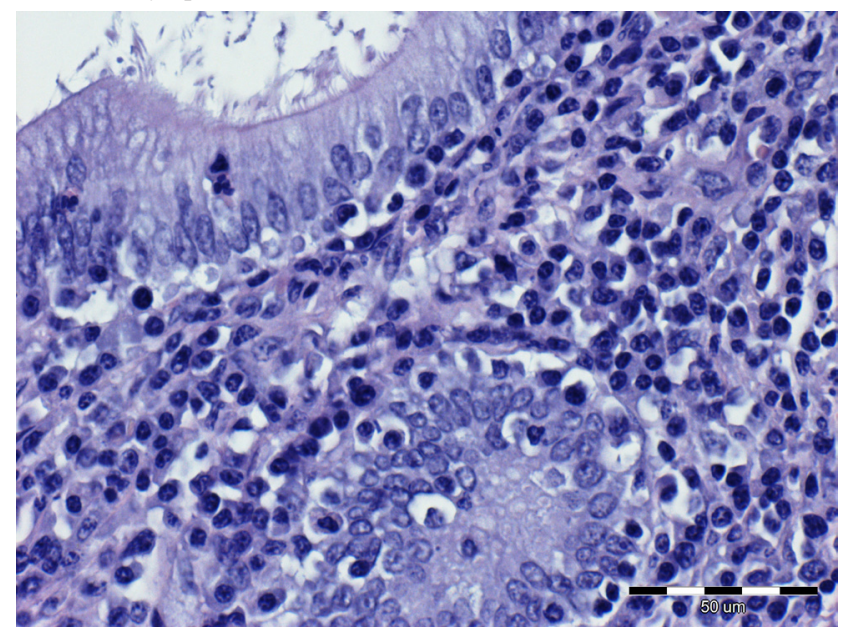

Figure 2. Infiltration composed mainly of lymphatic cells, single histiocytic cells, and granulocytes in tunica muscularis of the uterus 


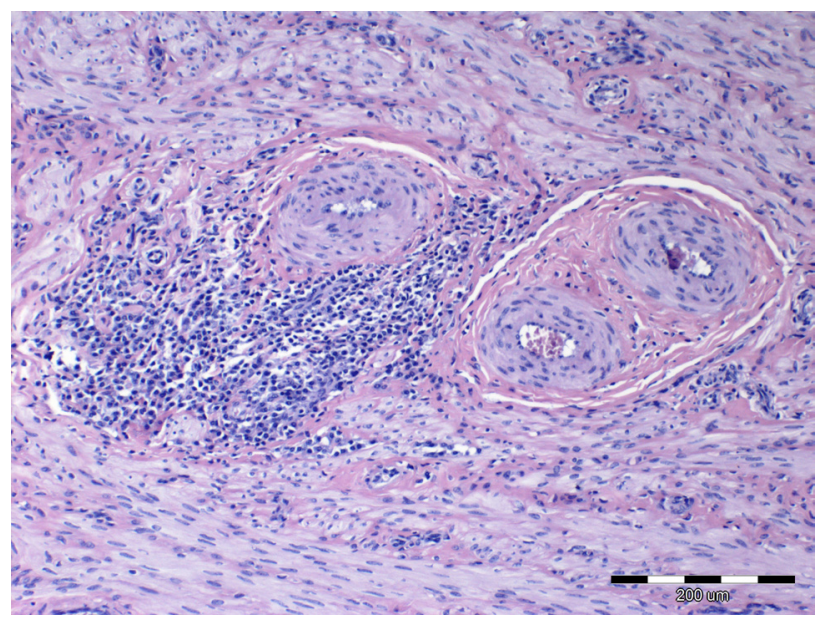

Figure 3. Perivascular infiltration composed of lymphatic cells localized in the myometrium

Reproductive disorders were observed in medium and large swine farms only. Among the 23 farms, reproduction disorders were recorded in 15 farms, out of which repetition of oestrus was identified in $6.6 \%$ farms, discharge from the reproductive tract after delivery was identified in $40 \%$ of farms, and dead or weak piglets in a litter were observed in $46.6 \%$ of farms.

\section{Discussion}

In the pig, infections with the Chlamydiaceae family generally seem to cause subclinical disease and the pathogen may be detected only with the use of diagnostic laboratory tests. Standard monitoring of chlamydia infection status in pigs involves serological examinations using a Chlamydia-group reactive lipopolysaccharide antigen (Sachse, 2003). This procedure has been previously used to detect Chlamydia spp. infection in the intestines of growing pigs and in conjunctiva swabs from finisher Belgian, Estonian, German, and Swedish pigs (Bagdonas, 2004; Becker et al., 2007; Englund, 2012). Illness cases are most often related to the above-mentioned species, whereas infections associated with C. psittaci or C. pecorum are quite sporadic (Schautteet and Vanrompay, 2011). In a German study, a high prevalence of mixed infections with $C$. suis and C. abortus in the lung and gut of pigs was observed (Sachse et al., 2005). In Finland, samples from the respiratory tract of 531 pigs suggested an association of Rhabdochlamydia spp. with respiratory disease (Niemi et al., 2011).

Chlamydial DNA was previously identified in $57.1 \%$ of the animals of a German wild boar population in Thuringia (Hotzel, 2004), suggesting a possible wildlife reservoir of these bacteria. Serological tests carried out in Germany in a group of 
1493 sows gave a positive result in 33\% of the animals with MMA, and repetition of oestrus as well as a high percentage of mortality among newly-born piglets occurred. However, an assessment of specific antibodies in blood samples in herds with or without reproductive problems did not identify any significant difference (Eggemann et al., 2000). A study in western Lithuania carried out at 24 swine farms indicated a season-dependent presence of antibodies against chlamydia in $0.1-25 \%$ of the animals assessed. That study found that the incidence of chlamydia infection in Lithuania was 4.1 times lower than in Ukraine (7.7\% vs. 31.6\%, respectively; Bagdonas, 2004). In addition, the prevalence of chlamydia infection in pigs from a province in China was 24.1-54.1\% (Xu et al., 2010).

Due to the intensification and development of specific approaches for swine production, research on the occurrence of chlamydia has focused on the possibility of the bacteria triggering disorders in reproduction. The frequency of chlamydia infection in porcine abortions varies depending on the methods used for antigen detection, region of the world, type of production system, and antibiotic used. In the United States, $60 \%$ of sows with reproduction disorders were found to have an infection, and in Eastern Europe, outbreaks of enzootic abortions were observed in highly industrialized large production systems (Stellmacher et al., 1983). In Switzerland, retrospective studies using immunohistochemistry and PCR revealed chlamydia in $5.8 \%$ of porcine abortion cases in smaller holdings (Thoma et al., 1997), whereas in Germany 3.9\% of abortion cases were found to be positive by Stamp smears and culture methods (Lehmann and Elze, 1997). Moreover, significantly higher percentages of seropositive sows were found in herds with abortion or infertility problems compared to healthy sows, but the serological methods were not fully credible, and a lack of detection of antibodies in the blood serum does not necessarily mean a lack of the pathogen in host cells (Wittenbrink, 1991; Wendt et al., 1998).

In swine, wide spreading of chlamydia may also occur through sexual contact, which can result in increased perinatal mortality of piglets. Research carried out in Switzerland and Germany using various diagnostic techniques (microbiological test, LPS-ELISA, IHC, PCR) detected the presence of C. psittaci and C. suis as well as sporadic $C$. pecorum in boar semen (Teankum et al., 2006). Kauffold et al. (2006) estimated that the prevalence of chlamydia was 5.2-24\% in boar semen. In addition, a correlation was found between seropositive sows in herds with seropositive boars.

An additional difficulty in detecting chlamydia infections is the fact that the bacteria are highly susceptible to chemicals that affect their lipid content and cell wall integrity. The cleaning of equipment and stables of infected pigs is important because chlamydia can survive for up to 30 days in faeces. In addition, disinfectants inactivate these pathogens, and active infections are treated with antibiotics. In general, tetracyclines are the drugs of choice to control the disease, but quinolones or macrolides can be administered in case of an infection with the tetracycline resistant C. suis strain. To date, no vaccines are available (Lenart et al., 2001; Di Francesco et al., 2008).

The results of our investigation showed that Chlamydia spp. infection in swine may be suspected more often based on clinical manifestation or serological methods. The histology is only an indicator of suspected infection with Chlamydia spp. 
since infiltration of lymphocytes is a common finding in normal uteri tissue, mainly depending on the stage of the reproductive cycle. Additional studies are needed to determine whether antimicrobial therapy (common in swine herds) may influence chlamydia detection status. Based on serology, 5.65\% of the samples in our study were positive. All samples tested by PCR were negative. Therefore, in Poland the Chlamydia spp. infection in swine may be suspected more often based on diagnosis by serology as compared to diagnosis by PCR.

\section{References}

Bagdonas J., Mauricas M., Gerulis K., Masilionis G., Martinov S. (2004). Incidence of pig chlamydiosis in Lithuania revealed by different techniques. Biotechnol. Biotec. Eq., 18: 166-176.

B e c k e r A., Lutz-Woh 1 grot L., B rugnera E., Lu Z.H., Z i m merman n D.R., Grimm F., Grosse Belage E., Kaps S., Spless B., Pospischll A., Vaughan L. (2007). Intensively kept pigs pre-disposed to chlamydial associated conjunctivitis. J. Vet. Med. A, Physiology, Pathology, Clinical Medicine, 54: 307-313

Di Francesco A., Donati M., Rossi M., Pignanelli S., Shurdhi A., Baldelli R., Ceven in i R. (2008). Tetracycline-resistant Chlamydia suis isolates in Italy. Vet. Rec., 163: $251-252$.

Eggemann G., Wendt M., Hoelzle L.E., Jaeger C., We iss R., Falling K. (2000). Prevalence of Chlamydia infections in breeding sows and their importance in reproductive failure. Deutsch. Tierärztl. Wschr., 107: 3-10.

Englund, S., af S egerstad C.H., A mlund F., Westergren E., Jacobson M. (2012). The occurrence of Chlamydia spp. in pigs with and without clinical disease. Vet. Res., 26: 8-9.

Everett K.D., Hornung L.J., Andersen A.A. (1999). Rapid detection of the Chlamydiaceae and other families in the order Chlamydiales: three PCR tests. J. Clin. Microb., 37: 575-80.

Hotzel H., B ernd t A., Melzer F., S a ch se K. (2004). Occurrence of Chlamydiaceae spp. in a wild boar (Sus scrofa L.) population in Thuringia (Germany). Vet. Microbiol., 103: 121-126.

Ka lt e n bö ck B., S chmeer N., S chneider R. (1997). Evidence for numerous ompl alleles of porcine Chlamydia trachomatis and novel Chlamydia species obtained by PCR. J. Clin. Microbiol., 35: $1835-1841$.

Kauffold J., Melzer F., Henning K., Schulze K., Leiding C., Sachse K. (2006). Prevalence of chlamydiae in boars and semen used for artificial insemination. Theriogenology, 65: $1750-1758$.

Le h m a n C., E l ze K. (1997). Keimspektrum infektiös bedingter Aborte bei Pferd, Rind, Schwein und Schaf von 1983-1993 in Nordwest- und Mittelthüringen. Tierärztl. Umschau, 52: 495-505.

L e $\mathrm{n}$ ar $\mathrm{t}$ J., A n d e r s e n A.A., R o c k e y D.D. (2001). Growth and development of tetracycline-resistant Chlamydia suis. Antimicrob. Agents Chemother., 45: 2198-2203.

L o n g b o t t o m D. (2004). Chlamydial infections of domestic ruminants and swine: new nomenclature and new knowledge. Vet. J., 168: 9-11.

N i e m c zu k K., S a ch s e K., S pra g u e L.D. (2007). Pathogenesis, epidemiology and zoonotic importance of animal chlamydiosis. NVRI Pulawy 2007, Ed. 1, pp. 1-94.

N i e m i S., Gre ub G., P u o la k k a in e n M. (2011). Chlamydia-related bacteria in respiratory samples in Finland. Microbes Infect., 13: 824-827.

Pall e n M.J., Wr e n B.W. (2007). Bacterial pathogenomics. Nature, 449: 835-842.

Rypuła K., Płoneczka-Janeczko K., Ni emczuk K., Kumala A., Pejsak Z. (2012). Epidemiological aspects of Chlamydia spp. infection in swine. Med. Weter., 10: 517-521.

S a ch s e K., G ro s s m a n n E., J äg e r C., D ill e r R., H o tze 1 H. (2003). Detection of Chlamydia suis from clinical specimens: comparison of PCR, antigen ELISA, and culture. J. Microbiol. Meth., 54: $233-238$. 
S a ch s e K., Hotzel H., S li c ke r s P., Elling er T., Eh ri ch t R. (2005). DNA microarray-based detection and identification of Chlamydia and Chlamydophila spp. Mol. Cell. Prob., 19: 41-50.

S chaut te et K., Van rom pay D. (2011). Chlamydiaceae infections in pig. Vet. Res., 42: 1-10.

Souriau A., Le Rouzic E., Bernard F., Rodolakis A. (1993). Differentiation of abortinginducing and intestinal strains of Chlamydia psittaci isolated from ruminants by a microimmunofluorescence test. Vet. Rec., 132: 217-219.

Stell ma cher H., Kielstein P., Hors ch F., Martin J. (1983). Zur Bedeutung der Chlamydien-Infektion des Schweines unter besonderer Berücksichtigung der Pneumonien. Monatsheft. Veterinäermed., 38: 601-606.

Teankum K., Pospischil A., Janett F., Buergl E., Brugnera E., Hoelzle K., Polkinghorne A., Wellenmann R., Zimmermann D.R., Borel N. (2006). Detection of chlamydia in boar semen and genital tracts. Vet. Microbiol., 116: 149-157.

Thoma R., Guscetti T., Schiller L., Schmeer N., Corboz L., Pospischil A. (1997). Chlamydiae in porcine abortion. Vet. Pathol., 34: 467-469.

Wendt M., Eggemann G., Wittenbrink M., Jäger C., Weis s R., Failing K. (1998). Prevalence of chlamydial infection in breeding sows. Proc. 15th International Pig Veterinary Society Congress, 5-9 July 1998. Birmingham, England, pp. 437-450.

Whe el hous e N., L ong bot to m D. (2012). Endemic and emerging chlamydial infections of animals and their zoonotic implications. Transbun. Emerg Dis., 59: 283-291.

W it te n brink M.M. (1991). Nachweis von Antikorpern gegen Chlamydien beim Schwein mit Hilfe eines Immunofluoreszenz- und eines Enzymimmunotests. Berl. München. Tieraärztl. Wschr., 104: 270-275.

X u M.J., He Y., Li ang R., Zhou D.H., L in R.Q., Y in C.C., He X.H., Li ang M., Zhu X.Q. (2010). Seroprevalence of Chlamydia infection in pigs from intensive farms in Southern China. J. Anim. Vet. Adv. 9: 1143-1145.

Accepted for printing 14 VIII 2013 